\title{
SELECTING THE OPTIMAL STRATEGY MODEL TO MINIMIZE DECISION FAILURES UNDER STRESS
}

\author{
*Ozgur DEMIRTAS \\ **Kubilay GOK \\ ***Nuray ATSAN \\ ****A. Asuman AKDOGAN \\ *Turkish Air Force, Turkey \\ ${ }^{* *}$ Winona State University, USA \\ ***Akdeniz University, Turkey \\ ****Erciyes University, Turkey
}

\begin{abstract}
Decision-making have been discussed within the psychology and management literature for decades. However literature on stress and decision making relationship is limited. Moreover, existing studies and the findings remain poorly organized, and the quantitative studies are not enough. In addition, the strategic management field mostly deals with stress and uncertainty concepts. Thus, the aim of this study is to select the optimal strategy model to minimize decision failures under stress. For this aim, we developed the basic theoretical models to explain decision-making behaviour under stress, and we used AHP methodology, which is more of a selection tool and is appropriate in decision making situations, where both quantitative and qualitative criteria have to be considered, to select the best alternatives among given strategy models. The literature review reveals that stress can impact each stage of the decision-making process. The results showed that vigilance approach, which belongs to conflict theory, is the most appropriate to minimize decision failures under stress.
\end{abstract}

Keywords: Decision-Making, Decision-Failures, Stress, Analytic Hierarchy Process.

\section{INTRODUCTION}

Although the association between stress and decision-making represents an important dimension of human behavior, this has not been explored extensively in the literature and the findings of the studies have been inconclusive (Kowalski \& Vaught, Scharf, 2003). An existing body of research evidence accumulated over the years shows that stress affects decision-making (Galvan \& Rahdar, 2013; Lazarus, 2000; Keinan, Friedland, \& Ben-Porath, 1987; Starcke et al., 2008). In contrast to a handful of studies showing partially positive effects, other studies have also revealed that stress affects decision-making negatively (Staal, 2004). While it is possible to think and act more rationally under non-stress conditions, the research evidence shows that decisions made under stressful conditions tend to be much more irrational. Early work on this topic showed that stressors result in decision-making that is hurried, unsystematic and lacking full consideration of options (Galvan \& Rahdar, 2013; Janis \& Mann, 1977; Mather \& Lighthall, 2012).

In today's dynamic changing environment, the concepts of stress and uncertainty become more apparent within the organizations. Parallel to these, managers have to cope with many stressful events while giving their decision. Thus, the concept of decision making under stress prominences in the strategic management field. Stress has also been shown to lead to a number of undesirable consequences, including a restriction or narrowing of attention, increased distraction, increases in reaction time and deficits in working memory (Driskell \& Salas, 1996). While making a decision, the level of stress experienced can vary from minor to intensive. For instance, deciding on which car to buy creates a certain degree of stress, while the health professionals in emergency department may have to make vital decisions, which may lead to a high level of stress. As the level of stress increases, its influence on decision-making becomes more evident. The high stress level may impede the decision maker's ability to engage systematically and objectively in careful analysis and choice. Several researchers assumed that intense stress leads to deterioration in a number of aspects of cognitive functioning that are essential to the decision-making process: cognitive flexibility, 
reasoning, discriminating the essential from the trivial, planning capabilities, concentration and the retrieval of information from memory (Keinan et al., 1987; Mandler, 1982; Raaijmakers, 1990).

A review of various theoretical models proposed for explaining decision-making under stress and pertaining research evidence about these models in extant literature form the basis of our paper about decision-making under stress. For example, in dual processing model, Starcke and Brand (2012) explored this matter based on the assumption that decision-makers make their decisions by using rational-analytical and intuitiveexperiential systems. On the other hand, another theoretical framework that is often used to explain decisionmaking under stress is the somatic marker hypothesis which claimed that decisions can be guided by somatic markers. In this study, the authors analyze this topic based on the models that focus on the stressors influencing the decision-making process. Thus, the primary purpose of this study is to select the optimal strategy model to minimize decision failures under stress. For this aim, we proposed strategies how to prevent decision failures that stem from perceived decision specific stress. For that end, we first introduced a review of the basic theoretical models advocated to explain the decision-making behavior under stress. Next, the methodology and the results of this study were presented. Finally, our paper concludes by offering suggestions to prevent decision failures stem from decision-making under stress and how to cope with it.

\section{LITERATURE REVIEW}

Although the influence of common causes, such as information overload, limitation of human information processing, group pressure, blinding prejudice, ignorance, organizational constraints, and bureaucratic politics are important, Janis and Mann (1977) emphasized that perceived stress in the decision-making process is a major cause of bad decisions and errors. In the literature review, stress has been identified as an important factor that tends to increase the number of task errors (Baradell \& Klein, 1993; Johnston et al., 1997; Keinan, 1987; LeBlanc, 2009). A review of decision-making under stress literature also showed that management researchers and theorists proposed four different theoretical models to explain the decisionmaking behavior under stress. These models are as follows: conflict-theory of decision-making, threatrigidity model of decision-making under stress, crisis model of decision-making under stress, and finally decision-making under time pressure model.

\section{Conflict-Theory of Decision Making}

This model is based on a behavioral analysis clarifying problem causes and formulation of alternatives under conflicting conditions. Janis and Mann (1977) treated decision stress as a dependent variable such as perceived risk or loss, availability of promising alternatives, and time limit to process information and evaluating each alternative. Furthermore, they approached the concept of decision-making stress as a context and a problem-related phenomenon. They also argued that the way one copes with resolving a difficult choice is determined by the presence or absence of three factors: (1) the awareness of loss or risk involved; (2) the hope in finding a promising solution to a challenging situation as well as the chance of avoiding it; and (3) the time available to evaluate and search for relevant information with respect to established alternatives.

Janis (1982) described five major behavioral patterns while trying to make decision-making under stress. These were as follows: (1) unconflicted adherence occurs when a decision-maker decides on continuing whatever s/he has been doing, ultimately ignoring the information about the risk of losses, (2) un-conflicted change happens when the decision-maker uncritically adopts whichever new course of action is most salient or most strongly recommended, (3) defensive avoidance take place when the decision-maker avoids conflict by procrastinating, shifting responsibility to someone else, or constructing wishful rationalizations and remaining selectively inattentive to relevant information, (4) hypervigilance takes place when a decisionmaker searches drastically for a way out of the dilemma and impulsively seizes upon a hastily contrived solution that seems to promise immediate relief, overlooking the full range of consequences of his/her choice because of intentional excitement and repetitive thinking. Janis, in its extremist form, refers to this behavioral pattern as panic, and finally (5) vigilance occurs when the decision-maker searches for relevant information, assimilates it in an unbiased manner, and appraises alternatives carefully before making a choice. Such approach is also referred to as the analytical decision-making behavior. 
Journal of Global Strategic Management | V. 9 | N. 1 | 2015-June | isma.info | 43-53 | DOI: 10.20460/JGSM.2015915627

In an assessment of those five decision-making behavior patterns we presented above, Janis (1982) concluded that the first two patterns may save time, and emotional wear-and-tear, especially for routine decisions, but if the decision-maker has to make a vital decision, it often leads to defective decision-making.

\section{Threat-Rigidity Model}

The second approach to the study of decision-making under stress is the "Threat-Rigidity Effect" model by Staw et al. (1981). This model is based on the analysis of previous literature from sociology, organizational theory, psychology, and social psychology. The collapse of many organizations is related to their failures to adapt to the changing conditions caused by a stressful environment (Staw et al., 1981). Under threatening conditions, individuals, groups and organizations react by becoming more rigid and more controlling (Staw et al., 1981; Plotnick et al., 2009). This model considers threat as an environmental event that has impending negative or harmful consequences for the entity; information processing and control was treated as the determination of rigidity. The model is based on the analysis of previous literature from sociology, organizational theory, psychology, and social psychology by Staw et al. (1981).

The threat-rigidity model is founded with a multi-level framework that outlines the decision-making under stress behavior at individual, group and organizational levels (Plotnick et al., 2009). Individual level analysis of threat rigidity approach based on three elements: the first one is the link between threat situations, psychological stress, and anxiety; the second one is the nature of cognitive manifestations of stress, anxiety and arousal; and, the third one is the level between cognitive manifestations of stress anxiety, arousal and properties of individual behavior. The basic premise of the group level model is that the threat path to groups may either come from external or internal sources. According to the model, if the threat is attributed to external sources, and if there is hope that the threat can be mediated, the group is expected to increase its internal cohesiveness, increase the leadership support and pressure for group uniformity. On the other hand, if the threat arises from deficiencies and dysfunctions of the internal operation of the group, it was predicted that cohesiveness and consensus will decrease. The last level of analysis is the organizational level response. The threat for the organization was described as a resource scarcity, competition or reduction in the size of the market. Organizational level policy may rely on prior knowledge and experience and on reducing the communication channel complexity which leads to a restriction of information processing. Thus, decisionmaking might lead to a centralization of authority through increased top-down information control; tendency to increase efficiency through cost-cutting or better allocation, or conservation of resources might also increase.

Staw et al. (1981) also argue that organizational leaders tend to become more rigid by centralizing decisionmaking, constricting the use of resources and limiting communication. This model indicates that environmental change leads to threats to the vital interests of the individuals, groups and organizations, which results in rigidity where preferred prior responses will not meet the demands of the new situation and will be inappropriate due to constant change takes place in the cultural, economic, political, legal, and technological environment of the business organizations. However, threat rigidity hypothesizes may be somewhat working under certain and stable conditions of environment.

\section{The Crisis Model}

Hermann (1963) was one of the first to use a theoretical approach to decision-making under a crisis situation. This early perspective is important since it influenced the future thinking in the study of decision-making under crisis (Billings et al., 1980). The three elements of Hermann's model are: a potential threat to the high priority goal of the organization: a surprise from lack of weariness about situations; and the existence of a short time period for decisions (Billings et al., 1980; Smart \& Vertinsky, 1977). Billings and his colleagues concluded that in Hermann's model, all of the three conditions must be present at the same time in order to consider an event a crisis. They also emphasized that research employing the crisis model did not produce consistent findings in support of the model elements. For instance, they asserted that element of surprise has had little empirical support; and should either be reformulated or dropped from the model. Moreover, the empirical evidence did not support the time measures; perceived time pressure was a factor rather than a time limit in making a decision. The only variable that got consistent empirical support was the threat; they assumed that smaller threats meant smaller probabilities of losses and/or less importance of goals. 


\section{Journal of Global Strategic Management | V. 9 | N. 1 | 2015-June | isma.info | 43-53 | DOI: 10.20460/JGSM.2015915627}

Billings et al. (1980) argued that the first step of defining a situation as a crisis should invo1ve perceiving the event in the environment which trigger the crisis. They maintained that this triggering event must be perceived, attended to, and evaluated with respect to a fixed reference point and/or a standard. They argued that this definition was inconsistent with the major decision-making literature; the first step in most decision-making processes is problem searching which violates some criteria relating to individuals, groups, or organizations. The next step of this model is to evaluate the size of discrepancy, and to decide upon the perceived seriousness of the problem. Because, the stage of the crisis have an influence on decision making process. Thus, the degree of perceived crisis is determined as a function of the interaction of three variables: perceived value of possible loss, probability of loss, and time pressure (Billings et al., 1980).

\section{Theory of decision-making under time pressure}

Acute stress has a rapid and time dependent effect on decision making (Pabst et al., 2013). Often individuals have to make decisions under deadlines. Stock market brokers, for instance, make important financial decisions under extreme time constraints while experiencing excessive noise, heat and antagonistic interpersonal interactions (Porcelli \& Delgado, 2009). This may be a daunting task that creates stress and cognitive strain. From this point of view, "theory of decision-making under time pressure" developed by Bronner (1982) has become a major theory of decision making under stress. Bronner (1982) determined three elements of time pressure: decision time, sensitivity, and problem intensity. First, the decision-maker must understand that time is an obligatory part of problem-solving; any violation would lead to a reduction in decision effectiveness. Second, differences in the cognitive structure of people will predict differing degrees of sensitivity to time pressure exposure. Third, Bronner (1982) stated that problem intensity reflects problem evaluation from the decision-maker's perspective; it reflects the subjective assessment of the situation.

Besides these three elements, he noted several symptoms of time pressure. Time pressure leads to the limitation of interaction among the decision-making units and less demand for information on the part of the decision-maker. Time pressure also limits the scope of the coordination activity in decision-making units. Thus, it is stated that time pressure is an important stressor (Keinan et al., 1987). Using a gambling paradigm in their examination of decision strategies, Zur and Breznitz (1981) found that decision makers under time pressure tended to make lower risk choices and spend more time viewing negative dimensions of the decision.

In addition, several researchers emphasized that under time constraints, decision makers try to boost up the decision-making process and if it is not possible then shift to the simplest strategy (Edland \& Svenson, 1993; Raaijmakers, 1990; Schutte, 2012; Staal, 2004; Wright, 1974).

\section{METHODOLOGY}

The aim of this study is to select the optimal strategy model to minimize decision failures under stress. For this aim, we used AHP methodology, which is more of a selection tool and is appropriate in decision making situations, where both quantitative and qualitative factors have to be considered, to select the best alternative among given strategy models (Geng \& Hu, 2012).

The AHP method is a multiple criteria decision-making tool that has been widely used related with decisionmaking (Saaty \& Vargas, 1994). The model includes pairwise comparisons among the factors of a given model (Bhutta \& Huq, 2002; Saaty, 1980). This method consist of a questionnaire for comparison of each element and geometric mean to arrive at a final solution.

Although there are many scales that can be used for quantifying managerial judgments, the scale given in Table 1 is used in this study (Saaty, 1980). The AHP concept also involves a set of systematic steps for problem solving with giving the relationships among the decision criteria (Kuo et al.,1999). Most of the studies indicated that AHP methodology has advantage over the conventional methods such as brain storming, delphi technique and Q-Sort analysis (Lai et al., 2002; Bhutta \& Huq, 2002; Demirtas, 2013; Kuo et al., 1999; Harker, 1987; Tummala et al., 1997; Su et al., 2003). 
Journal of Global Strategic Management | V. 9 | N. 1 | 2015-June | isma.info | 43-53 | DOI: 10.20460/JGSM.2015915627

Table 1 Analytic Hierarchy Measurement Scale

\begin{tabular}{|c|c|c|}
\hline $\begin{array}{l}\text { Reciprocal Measure of Intensity } \\
\text { of Importance }\end{array}$ & Definition & Explanation \\
\hline 1 & Equal importance & Two activities contribute equally to the objective \\
\hline 3 & Weak importance of one over another & $\begin{array}{l}\text { Experience and judgment slightly favor one activity } \\
\text { over another }\end{array}$ \\
\hline 5 & Moderate importance & $\begin{array}{l}\text { Experience and judgment strongly favor one } \\
\text { activity over another }\end{array}$ \\
\hline 7 & Strong importance & $\begin{array}{l}\text { An activity is strongly favored and its dominance is } \\
\text { demonstrated in practice }\end{array}$ \\
\hline 9 & Absolute importance & $\begin{array}{l}\text { The evidence favoring one activity over another is } \\
\text { of the highest possible order of affirmation }\end{array}$ \\
\hline $2,4,6,8$ & $\begin{array}{l}\text { Intermediate values between two } \\
\text { adjacent judgments }\end{array}$ & When compromise is needed \\
\hline Reciprocal of above & \multicolumn{2}{|c|}{$\begin{array}{l}\text { If activity } \mathrm{i} \text { has one of the above non-zero numbers assigned to it when compared } \\
\text { with activity } \mathrm{j} \text {, then } \mathrm{j} \text { has the reciprocal value when compared with } \mathrm{i} \text {. }\end{array}$} \\
\hline
\end{tabular}

\section{Sample and Data Collection}

The factors and sub-factors in our model were developed from the literature reviews and the interviews made by 7-management personnel, who are in the head of the production, quality, research and development (R\&D), maintenance, planning and budgeting departments at defence industry. The interviews are made by face to face. In the literature review, an optimal sample size is not given for AHP methodology, but the sample size in this study is higher than some others (Badri, 1999; Bascetin, 2007; Harbi, 2001; Harker, 1987).

After developing the factors and sub-factors, a second interview was made by the same sample. At the second interview, we wanted them to compare the criteria one-to-one using the AHP comparing scale. Then, the AHP methodology and its reliability analysis were being made.

\section{Analyses and Results}

In the AHP methodology, the decision making process starts with the establishment of the hierarchy as shown in Fig.1. In order to determine the importance of the alternatives, pair-wise comparisons were used.

As suggested by Saaty (1980), the geometric mean approach, instead of the arithmetic approach, is used to combine the individual pairwise comparison judgment matrices (PCJMs). 


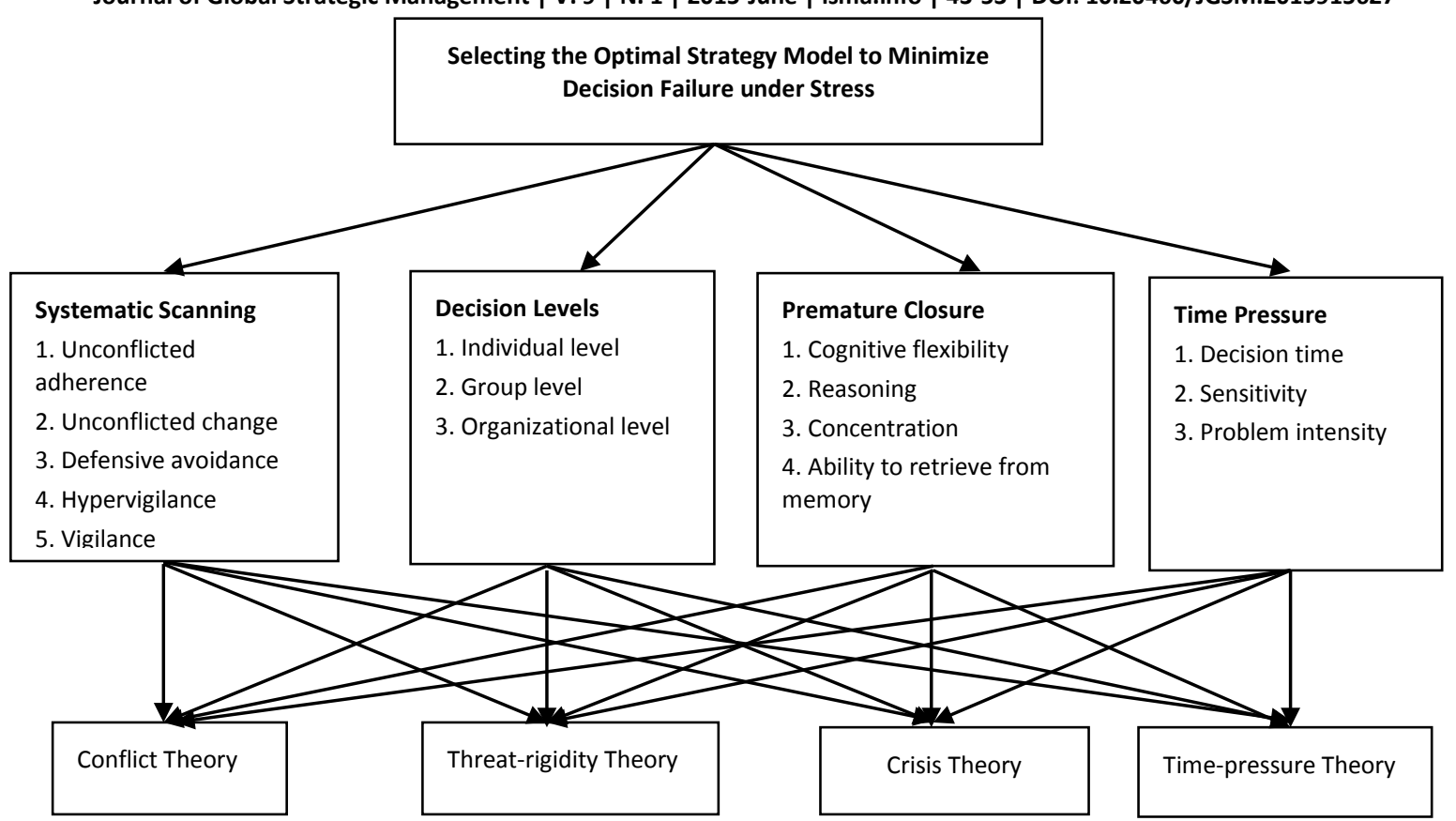

Figure 1: Hierarchy of the study

The pairwise comparison judgment matrices obtained from seven management personnel and data collection phase are combined using the geometric mean approach at each hierarchical level to obtain the corresponding consensus pairwise comparison judgment matrices. Each of these matrices is then interpreted into the corresponding largest eigen-value problem and is solved to find the normalized and unique priority weights for each criterion. For this study, conflict theory's reciprocal matrix (as an example in the machining technologies) is given in Table 2.

\section{Table 2 Pairwise comparisons judgment matrice for conflict theory}

\begin{tabular}{lllllll}
\hline & C1 & C2 & C3 & C4 & C5 & W \\
\hline Unconflicted Adherence (C1) & 1.00 & 1.41 & .29 & 3.65 & .14 & .12 \\
Unconflicted Change (C2) & .67 & 1.00 & .24 & .32 & .12 & .05 \\
Defensive Avoidance (C3) & 3.47 & 4.21 & 1.00 & 2.99 & .29 & .22 \\
Hypervigilance (C4) & .27 & 3.17 & .33 & 1.00 & .22 & .09 \\
Vigilance (C5) & 7.08 & 8.26 & 3.50 & 4.58 & 1.00 & .52 \\
\hline
\end{tabular}

W: Weighted vector; $\lambda=3.0017$; Consistency Index (CI): .0009; Consistency Ratio (CR): .0015

Analyses were made following the completion of the pairwise comparisons. The first stage of the analyses is to check the consistency of judgments. In the AHP method, the consistency of matrix in a pairwise comparison should be ensured. If the matrix is inconsistent, evaluating must be made until a consistency is achieved. The consistency ratio (CR) wanted to be smaller than .10 (Soma, 2003; Cox et al, 2000). In this study, Consistency Ratios (CR) for the conflict theory is .0015; threat-rigidity model is .0123; crisis model is .0699; time-pressure theory is .0973.

The second stage of the analyses is to calculate the relative weights of both main and sub-factors. As an example from the analyses, we gave the final weighted results for conflict theory as in Table 3. 
Journal of Global Strategic Management | V. 9 | N. 1 | 2015-June | isma.info | 43-53 | DOI: 10.20460/JGSM.2015915627

Table 3: Final results for conflict theory.

\begin{tabular}{lll}
\hline Sub-factors in the Conflict Theory & Weights & $\%$ \\
\hline Unconflicted Adherence (C1) & .1254 & $13 \%$ \\
Unconflicted Change (C2) & .0536 & $5 \%$ \\
Defensive Avoidance (C3) & .2352 & $24 \%$ \\
Hypervigilance (C4) & .0869 & $9 \%$ \\
Vigilance (C5) & .4988 & $50 \%$ \\
\hline
\end{tabular}

All of the AHP formulas are performed, and the final relative weights of the main and sub-factors that were considered in selecting the optimal strategy model in order to minimize decision failures, were obtained as in Table 4.

Table 4: Final results of the hierarchical model.

\begin{tabular}{|c|c|c|c|c|}
\hline Theory & Weights & Sub-factors & Weights & Global Weights \\
\hline & & Vigilance & $50 \%$ & $13 \%$ \\
\hline & & Defensive Avoidance & $24 \%$ & $6 \%$ \\
\hline \multirow[t]{4}{*}{ Conflict Theory } & .34 & Unconflicted Adherence & $13 \%$ & $3 \%$ \\
\hline & & Hypervigilance & $9 \%$ & $2 \%$ \\
\hline & & Unconflicted Change & $5 \%$ & $1 \%$ \\
\hline & & Organizational Level & $45 \%$ & $12 \%$ \\
\hline \multirow[t]{4}{*}{ Threat-rigidity Theory } & .28 & Group Level & $34 \%$ & $9 \%$ \\
\hline & & Individual Level & $21 \%$ & $5 \%$ \\
\hline & & Reasoning & $37 \%$ & $9 \%$ \\
\hline & & Concentration & $29 \%$ & $7 \%$ \\
\hline \multirow[t]{3}{*}{ Crisis Theory } & .21 & $\begin{array}{l}\text { Ability to retrieve from } \\
\text { memory }\end{array}$ & $21 \%$ & $5 \%$ \\
\hline & & Cognitive flexibility & $13 \%$ & $3 \%$ \\
\hline & & Decision time & $38 \%$ & $10 \%$ \\
\hline \multirow[t]{2}{*}{ Time-pressure Theory } & .17 & Sensitivity & $35 \%$ & $9 \%$ \\
\hline & & Problem Intensity & $27 \%$ & $6 \%$ \\
\hline
\end{tabular}

According to the global weights of the model, we have found that vigilance was the most important factor in determination of the minimization of decision failures under stress, and unconflicted change was the least significant factor in the model.

\section{DİSCUSSION AND CONCLUSION}

Risk and uncertainty are the inseperable parts of the decision-making process in the strategic management field. Decision-making process is concerned with a series of steps, namely recognition of problems or objectives, generating alternative courses of action, evaluating and/or ranking possible alternatives of action, making a choice from among them and implementing the selected course of action (Kowalski \& Vaught, 2003; Sarmany-Schuller, 2010). There is no question that stress can impact each stage of the decision-making process (Moschis, 2007). In this study, we aimed to select the optimum strategy model under stress with respect to the quantitative factors that were established from the existing stress and decision-making literature. An evaluation among the theories made using the Analytic Hierarcy Process. The results of the multi-criteria decision analysis showed that vigilance was the most important factor in determination of the minimization of decision failures under stress, and unconflicted change was the least significant factor in the model. We didn't find any parallel literature findings related with this result. But, we think that the defence industry contains highly technological improvements, and the decisions mostly given according to the existing environmental conditipns. Thus, the environmental and technological factors should have an important influence for the management team who make the pairwise comparisons for the analyses.

Although there are so many studies investigating the influence of stress on decision-making, there is surprisingly few work on examining this topic using analytical methodology. In this study, qualitative factors 


\section{Journal of Global Strategic Management | V. 9 | N. 1 | 2015-June | isma.info | 43-53 | DOI: 10.20460/JGSM.2015915627}

in decision making process transformed to quantitative values. Though many decisions must be made under stress and many decision situations elicit stress responses themselves (Starcke \& Brand, 2012), decision makers could enhance their decision-making performance and protect against potential decision failures (Whyte, 1991) by means of adapting certain coping strategies such as (1) using balance sheet exercise that was suggested by Janis (1982), (2) as suggested by Kruglanski (1986), using check-lists could prevent the potential failures by means of a preparing a check-list for all aspects of the alternatives, and before selecting the "best" alternative, these aspects should be compared against to the criteria check-list, (3) heightening the fear of failure by inserting several reminders into the decision-making process may be helpful to heighten the fear of failure. For instance, a few people may be assigned to remind the negative consequences of the actions, (4) as suggested by Billings et al. (1980), one of the significant sources of decision-making stress is the necessity of making a choice within a fixed time period. Thus, analyzing the sources of decision-making stress is another strategy to cope with decision failures, (5) using decision support systems whenever feasible in order to combine human judgment and the power of computer technology to improve the effectiveness and quality of decision-making outcomes (Phillips-Wren \& Adya, 2009), (6) Research findings also suggested that ordering task priorities is another ways to enhance the decision quality and prevent potential decision failures while making decisions under stress (Mann \& Tan, 1993).

Our review of extant research suggests that decision making under stress causes distortions in the information gathering, alternative generation, assessment of available choices, and finally in the stage of making a choice from among alternatives available to the decision-maker. By highlighting sources of decision-making stress and its implications for decision-making behavior, we hoped that organizations and their managers can adopt certain strategies to scan the information and alternatives without panic. We also hope that use of principles suggested by the different models and scholars may help managers to see their weaknesses in the decisionmaking behavior more clearly. The comparison of the criteria can serve as a check-balance system against non-rational and emotional reactions in the organizations. The other implication for the practice of management is that since the managers can commit themselves to any course of action, involving more people in the decision making and consulting the expert judgment can help managers to better evaluate the negative and positive consequences of their actions.

Overall, this study expands the understanding of the relationship between decision-making and stress by adding a different perspective to strategic management literature. However, this study has several limitations. First, the data were taken from manufacturing industry. Thus, the results in this study cannot be generalized to the other sectors. Second, the results in this study are just ranking of alternatives. These results must be taken into account with other scenerios such as economical, social or environmental conditions of the organizations. Future research should use different multi-criteria decision making techniques such as Analytical Network Process, Fuzzy AHP, or Fuzzy TOPSIS for comparative purposes. 


\section{REFERENCES}

Al-Harbi, K. M. A. S. (2001). Application of the AHP in project management.International journal of project management, 19(1), 19-27.

Badri, M. A. (1999). Combining the analytic hierarchy process and goal programming for global facility location-allocation problem. International Journal of Production Economics, 62(3), 237-248.

Baradell, J. G., \& Klein, K. (1993). Relationship of life stress and body consciousness to hypervigilant decision making. Journal of Personality and Social Psychology, 64(2), 267.

Bascetin, A. (2007). A decision support system using analytical hierarchy process (AHP) for the optimal environmental reclamation of an open-pit mine.Environmental Geology, 52(4), 663-672.

Bhutta, K. S., \& Huq, F. (2002). Supplier selection problem: a comparison of the total cost of ownership and analytic hierarchy process approaches. Supply Chain Management: An International Journal, 7(3), 126-135.

Billings, R. S., Milburn, T. W., \& Schaalman, M. L. (1980). A model of crisis perception: A theoretical and empirical analysis. Administrative Science Quarterly, 300-316.

Bronner, R. (1982). Decision making under time pressure: an experimental study of stress behavior in business management. Free Press.

Cox, A. M., Alwang, J., \& Johnson, T. G. (2000). Local preferences for economic development outcomes: analytical hierarchy procedure. Growth and Change, 31(3), 341-366.

Demirtas, O. (2013). Evaluating the core capabilities for strategic outsourcing decisions at aviation maintenance industry, Procedia-Social and Behavioral Sciences, 99, 1134-1143.

Edland, A., \& Svenson, O. (1993). Judgment and decision making under time pressure. In Time pressure and stress in human judgment and decision making(pp. 27-40). Springer US.

Galvan, A., \& Rahdar, A. (2013). The neurobiological effects of stress on adolescent decision making. Neuroscience, 249, 223-231.

Geng, W. L., \& Hu, Y. S. (2012). Selection of Outsourcing Supplier Based on AHP. Advanced Materials Research, 490, 2921-2925.

Harker, P. T. (1987). Alternative modes of questioning in the analytic hierarchy process. Mathematical Modelling, 9(3), 353-360.

Hermann, C. F. (1963). Some consequences of crisis which limit the viability of organizations. Administrative Science Quarterly, 61-82.

Janis, I. L. (1982). Groupthink: Psychological studies of policy decisions and fiascoes.

Janis, I. L., \& Mann, L. (1977). Decision making: A psychological analysis of conflict, choice, and commitment. Free Press.

Johnston, J. H., Driskell, J. E., \& Salas, E. (1997). Vigilant and hypervigilant decision making. Journal of Applied Psychology, 82(4), 614-625.

Keinan, G. (1987). Decision making under stress: scanning of alternatives under controllable and uncontrollable threats. Journal of personality and social psychology, 52(3), 639-651.

Keinan, G., Friedland, N., \& Ben-Porath, Y. (1987). Decision making under stress: Scanning of alternatives under physical threat. Acta Psychologica,64(3), 219-228.

Kowalski-Trakofler, K. M., Vaught, C., \& Scharf, T. (2003). Judgment and decision making under stress: an overview for emergency managers.International Journal of Emergency Management, 1(3), 278-289.

Kruglanski, A. W. (1986). Freeze-think and the Challenger. Psychology Today,20(8), 48-49.

Kuo, R. J., Chi, S. C., \& Kao, S. S. (1999). A decision support system for locating convenience store through fuzzy AHP. Computers \& Industrial Engineering, 37(1), 323-326. 
Journal of Global Strategic Management | V. 9 | N. 1 | 2015-June | isma.info | 43-53 | DOI: 10.20460/JGSM.2015915627

Lai, V. S., Wong, B. K., \& Cheung, W. (2002). Group decision making in a multiple criteria environment: A case using the AHP in software selection.European Journal of Operational Research, 137(1), 134-144.

Lazarus, R. S. (2000). Toward better research on stress and coping. American Psychologist, 55(6), 665-73.

LeBlanc, V. R. (2009). The effects of acute stress on performance: implications for health professions education. Academic Medicine, 84(10), 25-33.

Mandler, G. (1982). The structure of value: Accounting for taste. In Affect and cognition: The seventeenth annual Carnegie Symposium on Cognition

Mann, L., \& Tan, C. (1993). The hassled decision maker: The effects of perceived time pressure on information processing in decision making.Australian Journal of Management, 18(2), 197-209.

Mather, M., \& Lighthall, N. R. (2012). Risk and reward are processed differently in decisions made under stress. Current directions in psychological science,21(1), 36-41.

Moschis, G. P. (2007). Life course perspectives on consumer behavior. Journal of the Academy of Marketing Science, 35(2), 295-307.

Pabst, S., Brand, M., \& Wolf, O. T. (2013). Stress and decision making: a few minutes make all the difference. Behavioural brain research, 250, 39-45.

Phillips-Wren, G., \& Adya, M. (2009). Risky Decisions And Decision Support: Does Stress Make A Difference?. In Proceedings of JAIS Theory Development Workshop.

Plotnick, L., Turoff, M., \& Van Den Eede, G. (2009, January). Reexamining threat rigidity: implications for design. In System Sciences, 2009. HICSS'09. 42nd Hawaii International Conference on (pp. 1-10). IEEE.

Porcelli, A. J., \& Delgado, M. R. (2009). Acute stress modulates risk taking in financial decision making. Psychological Science, 20(3), 278-283.

Raaijmakers, J. G. (1990). Decision making under mental and physical stress.TNO Institute for Human Factors.

Saaty T.(1980), The analytic hierarchy process, McGraw-Hill International Book Company

Saaty, T. L., \& Vargas, L. G. (1994). Decision making in economic, political, social, and technological environments with the analytic hierarchy process(Vol. 7). Rws Pubns.

Salas, E., Driskell, J. E., \& Hughes, S. (1996). The study of stress and human performance. Stress and human performance(A 97-27090 06-53), Mahwah, NJ, Lawrence Erlbaum Associates, Publishers, 1996,, 1-45.

Sarmany-Schuller, I. (2010) Decision making under time pressure in regard to preferred cognitive style (analytical-intuitive) and study orientation, Studia Psychologica, 52(4), 285-290.

Schutte, L. M. (2012). Stress, time pressure, and decision making. Independent Studies and Capstones. 651.

Smart, C., \& Vertinsky, I. (1977). Designs for crisis decision units. Administrative science quarterly, 640657.

Soma, K. (2003). How to involve stakeholders in fisheries management-a country case study in Trinidad and Tobago. Marine Policy, 27(1), 47-58.

Staal, M. A. (2004). Stress, cognition, and human performance: A literature review and conceptual framework. Ames Research Center, Research Report.

Starcke, K., \& Brand, M. (2012). Decision making under stress: a selective review. Neuroscience \& Biobehavioral Reviews, 36(4), 1228-1248.

Starcke, K., Wolf, O. T., Markowitsch, H. J., \& Brand, M. (2008). Anticipatory stress influences decision making under explicit risk conditions. Behavioral neuroscience, 122(6), 1352-1360

Staw, B. M., Sandelands, L. E., \& Dutton, J. E. (1981). Threat rigidity effects in organizational behavior: A multilevel analysis. Administrative science quarterly, 501-524. 
Journal of Global Strategic Management | V. 9 | N. 1 | 2015-June | isma.info | 43-53 | DOI: 10.20460/JGSM.2015915627

Su, J. C. Y., Chen, S. J. G., \& Lin, L. (2003). A structured approach to measuring functional dependency and sequencing of coupled tasks in engineering design. Computers \& Industrial Engineering, 45(1), 195-214.

Tummala, V. R., Chin, K. S., \& Ho, S. H. (1997). Assessing success factors for implementing CE a case study in Hong Kong electronics industry by AHP.International Journal of Production Economics, 49(3), 265-283.

Whyte, G. (1991). Decision failures: Why they occur and how to prevent them.The Executive, 5(3), 23-31.

Wright, P. (1974). The harassed decision maker: Time pressures, distractions, and the use of evidence. Journal of applied psychology, 59(5), 555-561

Zur, H. B., \& Breznitz, S. J. (1981). The effect of time pressure on risky choice behavior. Acta Psychologica, 47(2), 89-104. 